\title{
ANALYSIS THE EFFECT OF HABIT AND PERCEIVED ENJOYMENT MEDIATED BY BEHAVIOURAL INTENTION TO ADOPTION ON STUDENTS USING MOBILE BANKING BNI
}

\author{
Indah Septiani $^{1}$ \\ Muhartini Salim $^{2^{*}}$ \\ M Yasser Iqbal Daulay ${ }^{3}$
}

Manajemen, Fakultas Ekonomi dan Bisnis, Universitas Bengkulu, Indonesia

\begin{abstract}
Abstrak
Tujuan penelitian ini adalah untuk menganalisis pengaruh kebiasaan dan kenyamanan penggunaan yang dimediasi oleh minat perilaku pada adopsi penggunaan mobile banking BNI di Universitas Bengkulu. Penelitian ini merupakan penelitian kauntitatif, dimana total sampel yang digunakan adalah 150 responden. Data dikumpulkan menggunakan teknik snowball sampling dan dianalisis menggunakan SEM PLS (partial least square). Berdasarkan hasil penelitian menjelaskan bahwa kebiasaan dan persepsi kenyamanan yang dimediasi oleh perilaku minat mendukung penggunaan mobile banking di Universitas Bengkulu. Penelitian ini memiliki beberapa keterbatasan seperti, sebaran responden yang kurang merata, serta ruang lingkup teoritis penelitian. Penelitian selanjutnya dapat menentukan responden yang lebih merata, serta dapat memperluas dan memodifikasi kerangka pemikiran penelitian agar dapat mengukur atau mengkaji lebih dalam mengenai variabel terkait dalam penelitian ini.

Kata Kunci: Kebiasaan, Kenyamanan Penggunaan, Minat Perilaku, Adopsi
\end{abstract}

\begin{abstract}
The purpose of this study aims to analyze the effect of habit and perceived enjoyment, mediated by behavioural intention on adoption in students using BNI mobile banking at university of Bengkulu. This research is a casual quantitative study. The total sample of the study is 150 respondents, data were collected using snowball sampling and analyzed using SEM PLS (partial least square). Based on the results of the study explained that habits and perceived enjoyment mediated by behavioural intention support the use of mobile banking at Bengkulu University. This study has several limitations such as, uneven distribution of respondents, and the theoretical scope of research. Subsequent research can determine respondents more evenly, and can expand and modify the research framework to be able to measure or study more deeply about the related variables in this study.
\end{abstract}

Keywords: Habit; Perceived Enjoymen; Behavioural Intention; Adoption.

Article History: Received: (11-02-2020); Revised: (29-03-2020); and Published: (30-04-2020) Copyright @ 2020 Indah Septiana, Muhartini Salim, M Yasser Iqbal Daulay

How to cite this article: Septiana, I., Salim, M., Daulay, M.Y.I. (2020). Analysis The Effect Of Habit And Perceived Enjoyment Mediated By Behavioural Intention To Adoption On Students Using Mobile Banking Bni. Managament Insight: Jurnal IImiah Manajemen. 15(1), 78-94 


\section{PENDAHULUAN}

Perkembangan teknologi di era globalisasi mengalami peningkatan yang cukup signifikan hingga mendominasi sebagian besar aktivitas manusia (Jun \& Chai, 2003). Manusia dan teknologi hidup berdampingan dan saling melengkapi kebutuhan satu dengan lainnya. Teknologi membuat segala sesuatu menjadi lebih praktis dan mudah untuk dilakukan, sehingga pekerjaan manusia yang sebelumnya sulit untuk dikerjakan bisa terealisasi dengan mudah, cepat, dan efisien seperti halnya dalam sektor perbankan (Suryo, 2005). Seperti mobile banking yang dapat dikaitkan dengan perilaku konsumen mulai dari kebiasaan (habit), kenyamanan penggunaan yang dirasakan (perceived enjoyment), niat perilaku (behavioural intention) dan adopsi (adoption) pada suatu teknologi mobile banking tersebut.

Pada penelitian yang dilakukan oleh Carpenter \& Reimers (2005) membuktikan bahwa habit berpengaruh terhadap behavioural intention. Selanjutnya penelitian yang dilakukan oleh Kim \& Malhotra (2005), menyatakan bahwa habit berpengaruh kuat terhadap adoption. Sigar (2016) menyatakan bahwa perceived enjoyment dapat memberikan pengaruh yang kuat secara signifikan terhadap behavioural intention. Hasil penelitian mengungkapkan bahwa perceived enjoyment berpengaruh terhadap adoption (Chen \& Tsai, 2007). Behavioural intention pada penelitian yang dilakukan oleh Jati \& Laksito (2012) menyatakan bahwa terdapat pengaruh kuat terhadap adoption. Sehingga behavioural intention memiliki pengaruh secara signifikan untuk memediasi antara habit dengan perceived enjoyment terhadap adoption pada penggunaan suatu sistem teknologi.

Dalam penggunaan teknologi informasi dan komunikasi di dunia perbankan relatif lebih maju dibandingkan sektor lainnya. Salah satu teknologi yang berkembang pada saat ini dan banyak digunakan adalah mobile banking. Mobile banking merupakan layanan perbankan yang berfungsi untuk memudahkan nasabah dalam melakukan transaksi perbankan tanpa perlu datang ke bank kecuali untuk transaksi setoran dan tarikan tunai. Keunggulan mobile banking yaitu nasabah dapat melakukan transaksi di mana saja dan kapan saja tanpa dibatasi waktu. Terdapat beberapa layanan pada mobile banking yaitu meliputi: transaksi finansial, transaksi non finansial, transfer dana, cek saldo dan pembayaran tagihan yang dilakukan lewat telepon seluler, pada suatu layanan sistem teknologi, mobile banking lebih pesat dari pada ATM (automatic teller machines) karena konsumen lebih menginginkan hal yang praktis serta efisiensi waktu dan tenaga.

Hal ini didasarkan pada potensi mahasiswa/i di Universitas Bengkulu yang pada dasarnya otomatis telah menjadi nasabah Bank BNI sebagai tujuan untuk melakukan transaksi yang berkaitan dengan kegiatan di Universitas Bengkulu, dan juga seberapa besar dampak pada layanan mobile banking dalam hal memengaruhi perilaku mahasiswa/i pada penggunaan transaksi perbankan. Hal ini diyakini juga bahwa penggunaan mobile banking memiliki potensi yang besar untuk berkembang pesat di 
wilayah Provinsi Bengkulu. Oleh karena itu penelitian ini dilakukan untuk mengetahui dan memahami tentang penerimaan para mahasiswa/i di Universitas Bengkulu terhadap layanan mobile banking dalam rangka mengindentifikasi faktor-faktor yang memengaruhi sikap mahasiswa/i di Universitas Bengkulu pada penggunaan layanan mobile banking tersebut.

\section{TINJAUAN PUSTAKA}

\section{Adoption}

Adoption adalah proses suatu pengambilan keputusan untuk menggunakan secara keseluruhan dari penerimaan dan penggunaan berkelanjutan dalam suatu produk, layanan maupun ide. Rogers (2003) menjelaskan bahwa konsumen melalui suatu proses pengetahuan, persuasi, keputusan dan konfirmasi sebelum mereka siap dalam hal mengadopsi suatu sistem tersebut. Jadi, adopsi atau penolakan terhadap suatu inovasi dimulai ketika konsumen menjadi sadar pada sistem tersebut (Rogers \& Shoemaker, 1971). Adoption merupakan perilaku penentu didalam teori TAM (theory of acceptance model)

Davis (1989) menyatakan bahwa teori adoption model ini dianggap sebagai model yang tepat untuk menjelaskan alasan mengapa menerima sesuatu hal yang berimplikasi pada perilakunya. Sikap seseorang terhadap penggunaan atau adopsi teknologi atau sistem tergantung pada manfaat yang dirasakan dan persepsi kemudahan penggunaan. Jogiyanto (2007) menambahkan bahwa sikap terhadap niat adopsi merupakan suatu evaluasi menyeluruh seseorang dalam melakukan suatu perilaku.

Adoption pada penggunaan layanan mobile banking dapat dikatakan sikap ataupun niat sebagai jumlah dari perasaan yang dirasakan seseorang untuk menerima suatu objek atau perilaku dan diukur dengan suatu prosedur (Jogiyanto, 2007). Pada konteks mobile banking akan memengaruhi keputusan nasabah apakah akan terus menggunakan layanan mobile banking atau memutuskan untuk tidak memakainya lagi. Niatan untuk menggunakan mobile banking akan muncul ketika seorang nasabah memiliki sikap positif berupa penerimaan terhadap mobile banking. Datta et al., (2010) menjelaskan tentang intensitas dalam penggunakan mobile banking, kepercayaan dalam menggunakan, dan peningkatan penggunaan untuk waktu yang akan datang.

\section{Habit}

Teori habit (kebiasaan) menggunakan teori konfirmasi harapan kebiasaan yang disebut dengan the expectation confirmation theory (ECT). Oliver (1980) menjelaskan bahwa teori konfirmasi harapan adalah motivasi utama dalam penggunaan suatu layanan berkelanjutan dari suatu produk/ layanan. Berdasarkan teori konfirmasi harapan diindikasikan bahwa perubahaan jumlah pengguna dipengaruhi oleh persepsi kenyamanan, kebiasaan dan keterlibatan penggunan. Hassan \& Hutasoit (2011) mengemukakan bahwa formulasi untuk meningkatkan kebiasaan, kepuasan konsumen 
dan loyalitas dapat dilakukan dengan cara melakukan pekerjaan pertama kali dengan benar, kemudian menangani komplain dengan efektif. Pendekatan experience confirmation berpandangan bahwa kebiasaan yang dilakukan pada tingkat kepuasan dipengaruhi perasaan positif dan negatif yang diasosiasikan konsumen dengan produk/layanan tertentu. Dengan kata lain, selain pemahaman kognitif mengenai diskonfirmasi harapan, perasaan yang timbul dalam proses penggunaan suatu sistem memengaruhi perasaan puas atau tidak puas terhadap produk atau layanan yang digunakan.

\section{Perceived Enjoyment}

Perceived enjoyment dapat didefinisikan sebagai kondisi dimana seorang individu menggunakan sebuah teknologi ketika menjalankan aktivitasnya dan merasa nyaman untuk dirinya sendiri (Davis, 1989). Menurut Bruner \& Kumar (2005) menjelaskan bahwa semakin tinggi tingkat kenyamanan yang dimiliki oleh pengguna teknologi informasi maka semakin baik sikap dari pengguna yang nantinya akan berkaitan dengan penerimaan teknologi sistem tersebut.

\section{Behavioural Intention}

Berdasarkan Theory of Planned Behavior oleh (Ajzen \& Davis, 1991) teori ini merupakan pengembangan dari teori sebelumnya dengan menambahkan satu konstrak varabel yaitu perceived behavioral control, artinya perilaku seseorang dapat disebabkan oleh suatu kondisi yang berada dalam control mereka dan ada pula yang diluar control mereka. Pengendalian perilaku individu dipengaruhi oleh faktor internal individu (berasal dari dalam diri) seperti pikiran, perasaan, keterampilan, dan faktor eksternal (berasal dari luar diri) seperti lingkungan, fasilitas, dan sebagainya (Fishbein \& Ajzen, 2010). Persepsi terhadap kontrol perilaku adalah bagaimana seseorang meyakini bahwa perilaku yang ditunjukkannya merupakan hasil pengendalian yang dilakukan oleh dirinya. Teori ini secara keseluruhan menjelaskan bahwa pada dasarnya manusia secara rasional akan mempertimbangkan implikasi atau dampak dari perilaku mereka sebelum memutuskan untuk melakukan secara nyata atau aktual perilaku tersebut, termasuk pendapat orang lain dan sikapnya terhadap perilaku tersebut (Schiffman dan Kank, 2008; Zeithmal et al. 1996).

\section{Pengaruh Habit terhadap Behavioural Intention}

Ajzen \& Madden (2005) menyatakan bahwa habit dapat membangun persepsi yang mencerminkan hasil pengalaman sebelumnya. Kim \& Malhotra (2005) menegaskan penggunaan sebelumnya merupakan prediktor yang kuat dalam penggunaan teknologi di masa mendatang. Hal ini mencerminkan perbedaan dalam pengolahan informasi yang dapat memengaruhi ketergantungan pada habit untuk berperilaku. Secara konseptual, habit lebih terkait dengan perilaku yang secara otomatis dibentuk oleh seseorang berdasarkan pada pengetahuan, pengalaman dan 
keterampilan dari waktu ke waktu (Venkatesh et al., 2012). Dengan demikian dapat di konseptualisasikan bahwa habit bersifat kognitif secara langsung maupun tidak langsung dengan memiliki dampak positif dari niat perilaku. Beberapa penelitian menjelaskan pengaruh positif dan signifikan antara variabel habit dengan behavioural intention (Pahnila et al., 2011; Ghozali, 2016; Kim dan Malhotra, 2005). Oleh karena itu, hipotesis yang dapat dikembangkan yaitu :

\section{H1: Habit berpengaruh positif terhadap behavioural intention.}

\section{Pengaruh Perceived Enjoyment Terhadap Behavioural Intention}

Kenyamanan sangat penting tidak hanya dalam penggunaan secara langsung tetapi juga dalam konteks secara tidak langsung (Jarvenpaa \& Todd, 1997; Blakney \& Sekely, 2003). Pada penelitian sebelumnya yang dilakukan oleh Jarvenpaa \& Todd (1997) perceived enjoyment sangat penting pada aktifitas secara tidak langsung. Maka dari itu terdapat hasil bahwa adanya pengaruh perceived enjoyment terhadap behavioural intention (Ulaan et al., 2016). Dari hasil penelitian sebelumnya yang dilakukan oleh (Koufaris, 2002) kenyamanan penggunaan memengaruhi niat perilaku pelanggan secara tidak langsung. Menurut Li et al., (2005) pengguna yang menganggap penggunaan sesuatu yang menyenangkan lebih cenderung berniat untuk terus menggunakannya. Kenyamanan dalam konteks mobile banking dapat dilihat sebagai sejauh mana aktivitas penggunaan layanan mobile banking dianggap sebagai suatu hal yang menyenangkan dalam dirinya sendiri dikarenakan lebih termotivasi yang didukung oleh motivasi intrinsik untuk memudahkan dalam segala hal transaksi yang ada pada sistem layanan mobile banking. Oleh karena itu hipotesis yang dapat dikembangkan yaitu:

\section{H2: Perceived enjoyment berpengaruh positif terhadap behavioural intention.}

\section{Pengaruh Habit terhadap Adoption}

Habit memiliki pengaruh terhadap penggunaan teknologi sebagaimana ditunjukkan (Venkatesh et al., 2012) yang menyatakan bahwa habit berpengaruh terhadap adoption dalam penggunaan teknologi secara langsung. (Heijen, 2004) habit berpengaruh positif terhadap adoption. Hal ini didukung dari penelitian (Japutra et al., 2014) terdapat pengaruh yang kuat antara habit pada saat menggunakan suatu mobile banking dengan memengaruhi perilaku adoption pada mobile banking yang mana akan mengarah pada reaksi positif konsumen terhadap suatu layanan atau sistem. penelitian terdahulu yang dikemukakan oleh (Scarpi, 2010) menemukan bahwa beberapa variabel penjelas yang membantu memperbaiki pemahaman tentang konsep kebiasaan dan mengadopsi. Penelitian terdahulu yang dikemukakan oleh (Baudry, 2016) seseorang yang memiliki pengaruh yang kuat dengan suatu layanan akan memengaruhi perilaku mereka untuk melakukan adoption terhadap suatu sistem teknologi untuk melihat suatu sistem tersebut dapat bersaing dengan sistem teknologi yang lainnya, dikarenakan adanya keinginan konsumen untuk menggunakan suatu 
layanan tersebut terhadap adoption. Oleh karena itu, hipotesis yang dapat dikembangkan yaitu:

\section{H3: Habit berpengaruh positif terhadap adoption}

\section{Pengaruh Perceived Enjoyment terhadap Adoption}

Perceived enjoyment telah direkomendasikan oleh peneliti sebagai suatu yang berguna dalam memahami niat perilaku konsumen untuk mengadopsi suatu layanan, seperti yang dikatakan oleh (Teo, 2001) hasil penelitiannya menunjukan bahwa perceived enjoyment memiliki pengaruh yang signifikan terhadap adoption dalam memahami niat perilaku untuk menggunakan suatu mobile banking. Oleh karena itu, hipotesis yang dapat dikembangkan yakni:

\section{H4: Perceived enjoyment berpengaruh positif terhadap adoption.}

\section{Pengaruh Behavioural Intention Terhadap Adoption}

Pengaruh behavioral intention terhadap adoption juga dipengaruhi terhadap suatu pengalaman. Dengan meningkatnya pengalaman, konsumen memiliki lebih banyak kesempatan untuk memperkuat kebiasaan mereka karena memiliki lebih banyak waktu untuk melakukan perilaku yang terkait (Kim \& Malhotra, 2005). Akibatnya, efek dari behavioural intention pada penggunaan teknologi akan meningkatkan suatu pengalaman dari adoption. Menurut (Kim, 2005) behavioural intention berpengaruh secara signifikan terhadap adoption.

Dalam penelitian terdahulu menurut (Alalwan et al., 2017) menjelaskan bahwa behavioural intention penggunaan suatu mobile banking akan berpengaruh secara positif dalam adoption suatu layanan tersebut dengan adanya keamanan dan kenyamanan yang membuat suatu individu berniat untuk menggunakan suatu layanan mobile banking tersebut. Menurut (Bhattacherjee et al., 2008) penelitian yang dilakukannya menunjukkan hasil adanya hubungan behavioural intention berpengaruh positif terhadap adoption karena para pengguna mobile banking memerlukan faktor kenyamanan penggunaan untuk memberikan data pribadi pada mobile banking yang memerlukan data untuk bisa login dan memudahkan untuk bertransaksi. Penelitian sebelumnya menunjukkan bahwa kenyamanan penggunaan yang tinggi menghasilkan niat perilaku yang tinggi untuk mengadopsi suatu layanan mobile banking (McKnight \& Chervany, 2002). Oleh karena itu hipotesis yang dapat dikembangkan sebagai berikut :

\section{H5: Behavioural intention berpengaruh positif terhadap adoption.}

\section{Pengaruh Habit Dimediasi Behavioural Intention Terhadap Adoption}

Habit memiliki pengaruh terhadap penggunaan teknologi sebagaimana ditunjukkan Venkatesh et al., (2012) yang menyatakan bahwa habit berpengaruh terhadap penggunaan teknologi secara langsung dan juga dimediasi oleh behavioral intention. Penelitian terdahulu yang dikemukakan oleh (Alalwan et al., 2017) ada beberapa variabel penjelas membantu memperbaiki pemahaman tentang konsep 
kebiasaan, niat perilaku dan adopsi. Berdasarkan variabel yang dikaitkan dengan variabel independen yaitu, habit sebagai variabel mediasi yaitu behavioural intention dan variabel dependen (yaitu, adoption) mengenai mobile banking. Ye \& Potter, (2011) menjelaskan bahwa habit memengaruhi niat perilaku untuk mengadopsi suatu layanan mobile banking. Bauer et al., (2005) menjelaskan habit berpengaruh positif terhadap behavioural intention serta memiliki pengaruh langsung terhadap adopsi teknologi.

Berdasarkan theory of planned behaviour (TPB) bahwa niat berperilaku berpengaruh terhadap teori perilaku yang banyak diadopsi dari berbagai model variabel. Teori ini mengatakan bahwa variabel behavioural intention sebagai mediasi dari kebiasaan dan adopsi pada teknologi (Ajzen, 1991). Hal tersebut mengartikan bahwa adanya peran mediasi pada habit pada behavioural intention terhadap adoption. Maka oleh sebab itu, hipotesis yang dikembangkan yakni :

H6: habit dimediasi behavioural intention berpengaruh positif terhadap adoption.

Pengaruh perceived enjoyment dimediasi behavioural intention terhadap adoption

Venkatesh et al. (2012) mengatakan bahwa perceived enjoyment dan behavioural intention berpengaruh positif terhadap adoption. Kuo et al. (2009) menjelaskan kenyamanan penggunaan, niat perilaku dan niat adopsi berpengaruh positif terhadap adopsi konsumen yang telah memiliki kesetiaan terhadap suatu merek atau layanan terhadap suatu sistem akan memengaruhi sikap konsumen untuk melakukan perilaku yang membuat suatu merek atau layanan untuk diadopsi, pada adoption yang dipengaruhi oleh hasrat keinginan konsumen untuk mengadopsi suatu layanan atau merek untuk melakukannya dengan adanya suatu niat perilaku dalam penggunaanya (behavioural intention). Sebaliknya, jika keinginan konsumen untuk mengadopsi suatu produk atau layanan akan dimulai dari niat perilaku seorang konsumen untuk mengadopsinya dan terjadinya suatu kenyamanan penggunaan meskipun tidak memiliki pengalaman langsung pada penggunaan layanan pada mobile banking, hal ini diyakini pada suatu merek atau layanan tersebut terjadi karena kepusaan konsumen untuk menggunakan suatu layanan teknologi. Hal tersebut mengartikan bahwa adanya peran mediasi perceived enjoyment pada behavioural intention terhadap adoption. Oleh karena itu, hipotesis yang dapat dikembangkan yakni:

H7: perceived enjoyment dimediasi behavioural intention berpengaruh positif terhadap adoption. 


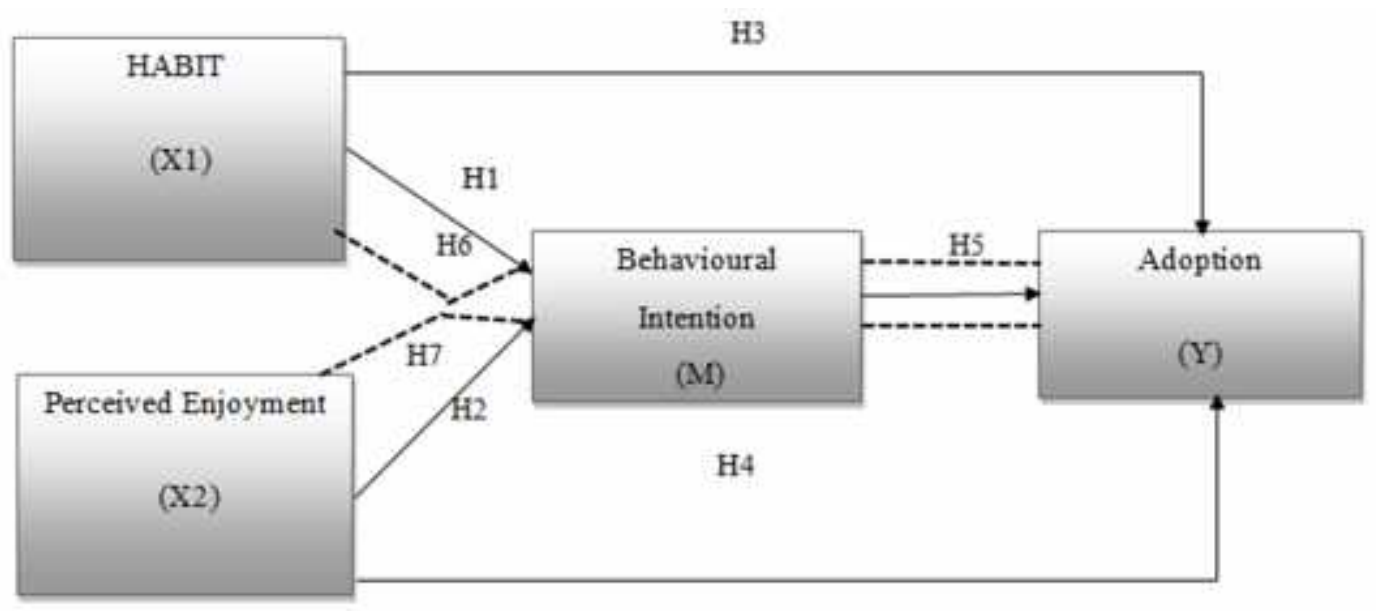

Gambar 1. Kerangka Penelitian

\section{METODE PENELITIAN}

Jenis penelitian yang digunakan dalam penelitian ini adalah penelitian kuantitatif. Penelitian kuantitatif ini merupakan studi untuk menguji hipotesis yang biasanya menjelaskan sifat hubungan tertentu dua atau lebih faktor dalam situasi Habit, Perceived Enjoyment, Behavioural Intention dan Adoption (Sekaran, 2007). Hal tersebut sesuai dengan tujuan dalam penelitian ini, yaitu untuk menguji hipotesis yang diajukan supaya dapat menjelaskan pengaruh variabel bebas terhadap variabel terikat.

Pengumpulan data penelitian ini menggunakan kuisioner tertutup secara online untuk mengukur Habit, Perceived Enjoyment, Behavioural Intention dan Adoption pada mahasiswa yang menggunakan mobile banking BNI di Universitas Bengkulu. Teknik pengambilan sampel yang digunakan pada penelitian ini adalah metode nonprobability sampling dalam bentuk snowball sampling. Dari 170 kuesioner yang diperoleh kemudian didefinisikan ada sebanyak 20 kuesioner yang tidak dapat diolah, dikarenakan tidak masuk dalam kriteria sampel yang ada di screening question seperti: bukan mahasiswa/i di Universitas bengkulu, mahasiswa/i yang tidak menggunakan mobile banking yang ikut mengisi kuesioner tersebut, dan terdapat juga kuesioner yang tidak diisi dengan lengkap oleh responden. Sehingga jumlah kuesioner yang dapat diolah sebanyak 150 responden. Dalam penelitian ini menggunakan SmartPLS (v.3.2.9) untuk menganalisis data.

Berdasarkan jawaban dari 150 responden, mayoritas responden adalah perempuan sebanyak 111 atau 74\% responden, sedangkan responden laki-laki sebanyak 39 atau $26 \%$ responden. Sebaran terbanyak responden yaitu yang berjenis kelamin perempuan hal ini dikarenakan perempuan lebih sering menggunakan mobile banking BNI untuk mempersingkat tenaga dan waktu yang dikeluarkan untuk bertransaksi secara langsung. Sehingga mereka memilih menggunakan mobile banking yang dapat mempermudah kegiatan transaksi mereka. Oleh karena itu, mayoritas 
responden dalam penelitian ini adalah responden dengan jenis kelamin perempuan. Karakteristik demografi responden dapat dilihat pada Tabel 1.

Tabel 1 Demografi Responden

\begin{tabular}{|c|c|c|c|c|}
\hline \multirow{2}{*}{$\begin{array}{c}\text { No } \\
1\end{array}$} & \multicolumn{2}{|c|}{ Karakteristik Demografi } & \multirow{2}{*}{$\begin{array}{c}\text { Frekuensi } \\
111\end{array}$} & \multirow{2}{*}{$\begin{array}{c}\text { Persentase } \\
74 \%\end{array}$} \\
\hline & Jenis Kelamin & Perempuan & & \\
\hline & & Laki-laki & 39 & $26 \%$ \\
\hline \multirow[t]{3}{*}{2} & Usia & 16-19 Tahun & 23 & $15,3 \%$ \\
\hline & & 20-24 Tahun & 111 & $74 \%$ \\
\hline & & >24Tahun & 16 & $10,6 \%$ \\
\hline \multirow[t]{4}{*}{3} & Semester & II & 10 & $6,6 \%$ \\
\hline & & IV & 38 & $25,3 \%$ \\
\hline & & VI & 76 & $50,6 \%$ \\
\hline & & $>$ VIII & 26 & $17,3 \%$ \\
\hline \multirow[t]{5}{*}{4} & Seberapa penting Anda & Sangat Penting & 64 & $42,6 \%$ \\
\hline & menggunakan mobile banking BNI & Penting & 86 & $57,3 \%$ \\
\hline & untuk keperluan kampus maupun & Tidak Penting & 0 & $0 \%$ \\
\hline & pribadi & Sangat Tidak & 0 & $0 \%$ \\
\hline & & Penting & & \\
\hline \multirow[t]{3}{*}{5} & Lama menggunakan mobile & $<3$ Bulan & 23 & $15,3 \%$ \\
\hline & banking BNI di Universitas & 3-6 Bulan & 49 & $32,6 \%$ \\
\hline & Bengkulu & $>6$ Bulan & 78 & $52 \%$ \\
\hline
\end{tabular}

Sumber : Data Primer, 2019

Sebaran responden berdasarkan usia terbanyak terdapat pada rentang usia mahasiswa 20-24 tahun yaitu sebanyak 111 orang atau $74 \%$. Hal ini karena pada usia tersebut responden dianggap berada pada usia produktif untuk saling berinteraksi dengan sesama pengguna dan mereka sudah mulai mengerti akan fungsi atau kegunaan mobile banking. Pengguna pada usia produktif tersebut sangat tepat untuk dijadikan sampel karena mereka akan mudah untuk menilai perasaan mereka saat menggunakan mobile banking.

\section{HASIL PENELITIAN}

Hasil penelitian ini menunjukan bahwa habit berpengaruh positif signifikan terhadap behavioural intention, terbukti dengan nilai T-statistik lebih besar dari nilai T-tabel $(10,845>1,96)$ dan $p$-values 0,000 atau $p$-values $\leq 0,05$ sehingga $\mathrm{H} 1$ diterima. Hal ini didukung oleh penelitian dari Ajzen \& Madden (2005) habit dapat membangun persepsi yang mencerminkan hasil penggunaan dari teknologi, konsumen yang menggunakan teknologi seperti mobile banking BNI membutuhkan suatu kebiasaan untuk meyakinkan jika dengan menggunakan teknologi baru dengan sistem yang mudah dipahami dan mudah untuk dijalankan dalam melakukan semua kegiatan transaksi, para konsumen akan merasa ingin terus menggunakan teknologi di dalam

Mediated By Behavioural Intention To Adoption On Students Using Mobile Banking BNI. 
semua aktivitas yang mereka butuhkan tanpa harus merasa kesulitan dalam menjalankan teknologi tersebut.

Secara praktis hasil penelitian ini juga memberikan kontribusi penting terutama bagi Bank BNI untuk selalu meningkatkan transformasi pada setiap perubahan yang mampu beradaptasi dengan cepat, fleksibel kepada nasabah bank sehingga nasabah akan terus menggunakan mobile banking BNI. Pada penelitian ini menemukan bahwa Bank BNI telah mampu memberikan efek yang positif terhadap kebiasaan dan niat berperilaku nasabah untuk menggunakan mobile banking dikarenakan konsumen menginginkan hal yang praktis. Hasil pengujian hipotesis dapat dilihat pada Tabel 2.

Tabel 2. Hasil Pengujian Hipotesis

\begin{tabular}{ccccccc}
\hline & $\begin{array}{c}\text { Original } \\
\text { Sample } \\
\text { (O) }\end{array}$ & $\begin{array}{c}\text { Sample } \\
\text { Mean } \\
\text { (M) }\end{array}$ & $\begin{array}{c}\text { Standard } \\
\text { Deviation } \\
\text { (STDEV) }\end{array}$ & $\begin{array}{c}\text { T Statistics } \\
\text { (IO/STDEV } \\
\text { I) }\end{array}$ & P Values & \\
\hline BI -> AD & 0,442 & 0,445 & 0,069 & 6,395 & $\mathbf{0 , 0 0 0}$ & Diterima \\
HT -> AD & 0,632 & 0,632 & 0,045 & 5,359 & $\mathbf{0 , 0 0 0}$ & Diterima \\
HT -> BI & 0,620 & 0,622 & 0,057 & 10,845 & $\mathbf{0 , 0 0 0}$ & Diterima \\
PE -> AD & 0,275 & 0,275 & 0,055 & 2,782 & $\mathbf{0 , 0 0 0}$ & Diterima \\
PE -> BI & 0,270 & 0,268 & 0,067 & 4,011 & $\mathbf{0 , 0 0 0}$ & Diterima \\
HT>BI>AD & 0,274 & 0,277 & 0,051 & 5,397 & 0.000 & Diterima \\
PE>BI $>$ AD & 0,119 & 0,119 & 0,036 & 3,306 & 0.001 & Diterima \\
\hline
\end{tabular}

Sumber: Data Primer (2019)

Hasil uji t menunjukan bahwa variabel perceived enjoyment berpengaruh positif signifikan terhadap behavioural intention, terbukti dengan nilai T-statistik lebih besar dari nilai T-tabel $(4,011>1,96)$ dan $p$-values 0,000 atau $p$-values $\leq 0,05$ sehingga $\mathrm{H} 2$ diterima. Hal ini menunjukan bahwa semakin tinggi kenyamanan dalam penggunaan pada layanan teknologi mobile banking BNI, maka semakin besar niat berperilaku untuk mengunakan suatu sistem tersebut, dan sebaliknya semakin rendahnya kenyamanan dalam pengunaan suatu sistem teknologi mobile banking BNI maka akan semakin tidak ada niat perilaku dari nasabah untuk menggunakannya. Hal ini sejalan juga dengan penelitian yang didukung oleh (Blakney \& Sekely, 2003; Koufaris, 2002; Venkatesh et al., 2012; Dai \& Palvi, 2009; Van, 2003) kenyamanan dalam penggunaan sangat penting pada penggunaan secara langsung, penggunaan suatu sistem dengan kenyamanan yang dirasakan mungkin merupakan konstruk penting dalam penelitian tentang memahami nasabah yang menggunakan mobile banking BNI.

Secara praktis hasil penelitian ini memberikan kontribusi penting terutama bagi bank BNI untuk selalu memberikan kenyamanan baik dari segi pelayanan langsung maupun tidak langsung yaitu pada layanan digital, kenyamanan penggunaan yang dirasakan nasabah pada saat menggunakan layanan mobile banking dari niat perilaku nasabah akan menimbulkan kesenangan dari penggunaan mobile banking yang sangat bermanfaat bagi kebutuhan nasabah dalam halnya bertransaksi. Selain itu, bank BNI

Mediated By Behavioural Intention To Adoption On Students Using Mobile Banking BNI. 
harus memberikan keamanan pada mobile banking dikarenakan pada semua pelayanan transaksi digital mempunyai kelemahan yang membuat nasabah khawatir pada penggunaan mobile banking, sehingga bank BNI harus lebih memberikan kontribusi dan kepercayaan kepada nasabah yang menggunakan layanan digital yaitu mobile banking.

Variabel habit berpengaruh positif signifikan terhadap adoption, terbukti signifikan dengan nilai T-statistik lebih besar dari nilai T-tabel $(5,359>1,96)$ dan $p$ values 0,004 atau $p$-values $\leq 0,05$ sehingga H3 diterima. Hal ini menunjukan bahwa semakin tinggi tingkat kebiasaan yang berkaitan dengan mengadopsi suatu sistem teknologi mobile banking $\mathrm{BNI}$, maka mahasiswa semakin mudah bertransaksi tanpa harus ke ATM terlebih dahulu, dan sebaliknya semakin rendahnya tingkat kebiasaan terhadap adopsi mobile banking, maka penggunaan aplikasi mobile banking akan semakin menurun. Hasil penelitian didukung oleh (Japutra et al., 2014; Scarpi, 2010) terdapat pengaruh yang kuat antara habit pada saat menggunakan suatu mobile banking dengan memengaruhi perilaku adoption yang mana akan mengarah pada reaksi positif konsumen terhadap suatu layanan atau sistem.

Secara praktis, hasil penelitian ini juga memberikan kontribusi penting terutama bagi Bank BNI untuk selalu memberikan pelayanan untuk mengadopsi layanan mobile banking, dikarenakan adanya keinginan untuk menggunakan layanan tersebut yang berasal dari keputusan untuk mengadopsi layanan tersebut. Hal ini menunjukan pentingnya kesadaran pada pihak Bank BNI untuk pemasar yang dapat memahami target dari perilaku nasabah mengenai persoalan tentang mobile banking bukan hanya sekedar sebatas logo dan tagline pada mobile banking semata yang sebenarnya yang akan memberikan nilai tambah yang memuaskan bagi nasabah untuk membuat nasabah tertarik mengadopsi layanan mobile banking $\mathrm{BNI}$ ini.

Variabel perceived enjoyment berpengaruh positif signifikan terhadap adoption, terbukti dengan nilai T-statistik lebih besar dari nilai T-tabel $(2,782>1,96)$ dan $p$ values 0,019 atau $p$-values $\leq 0,05$ sehingga $\mathrm{H} 4$ diterima. Hal ini menunjukan bahwa semakin tinggi tingkat kenyamanan dalam penggunaan pada suatu sistem teknologi, maka konsumen akan terus menggunakannya, dan sebaliknya semakin rendahnya tingkat kenyamanan dalam penggunaan pada suatu sistem teknologi maka konsumen akan semakin ragu dalam menggunakan suatu sistem teknologi mobile banking. Hal ini sejalan dari penelitian Lu et al., (2009) yang menemukan bahwa kenyamanan dalam penggunaan berpengaruh erat terhadap adopsi pada mobile banking, konsep seperti ini diterapkan dalam studi tentang berbagai konteks seperti bertransaksi pembayaran dan transfer, karena hal-hal seperti itu dapat memberikan pengalaman yang membuat seseorang akan fokus pada kenyamanaan penggunaan sistem teknologi mobile banking terhadap aktivitas yang dilakukan dan hanya memperhatikan apa yang sedang dikerjakan.

Secara praktis, hasil penelitian ini juga memberikan kontribusi penting terutama bagi Bank BNI untuk selalu memberikan kemudahan pada pengguna mobile 
banking, yang akan diterapkan dengan konteks seperti bertransaksi melalui pembayaran dan transfer, karena hal-hal ini seperti itu dapat memberikan pengalaman yang membuat nasabah akan fokus pada kenyamanan penggunaan yang dirasakan pada mobile banking terhadap aktivitas yang dilakukan nasabah dan memperhatikan apa yang sedang dikerjakannya. Hal ini menunjukan pentingnya kesadaran pada Bank BNI untuk memperbaharui setiap fitur yang ada pada mobile banking sehingga untuk meminimalisir adanya gangguan pada mobile banking dan memberikan kepercayaan nasabah untuk melayani setiap keluhan nasabah, sehingga nasabah akan menimbukan persepsi kenyamanan terhadap pengguna mobile banking yang akan membaut nasabah merasa nyaman saat menggunakan mobile banking BNI.

Variabel behavioural intention berpengaruh positif signifikan terhadap adoption, terbukti dengan nilai T-statistik lebih besar dari nilai T-tabel (6,395 $>1,96)$ dan $p$-values 0,000 atau $p$-values $\leq 0,05$ sehingga H5 diterima. Hal ini menunjukan bahwa semakin tinggi tingkat sikap dalam niat berperilaku pada mahasiswa yang menggunakan mobile banking $\mathrm{BNI}$, dan sebaliknya semakin rendahnya tingkat sikap dalam niat berperilaku pada pengguna mobile banking BNI maka akan semakin menurun pengguna mobile banking BNI. Penelitian ini juga didukung oleh penelitian Kim \& Malhotra (2005) yang menyatakan bahwa niat pada perilaku memiliki dampak yang positif signifikan terhadap adopsi yang juga dipengaruhi oleh suatu pengalaman dalam suatu penerimaan teknologi.

Secara praktis hasil penelitian ini juga memberikan kontribusi penting terutama bagi bank BNI yang memberikan proses kepuasaan yang dirasakan nasabah terhadap penyedia layanan, kepuasaan yang dirasakan nasabah terhadap mobile banking akan memberikan pengaruh perilaku niat yang tinggi atau rendah tergantung dari seberapa besar kepuasaan nasabah pada saat menggunakan layanan tersebut. Sehingga bank BNI pada penyedia layanan harus memberikan kontribusi yang maksimal terhadap nasabah, sehingga nasabah mendapatkan pengalaman menggunakan mobile banking yang akan mengadopsi layanan pada suatu penerimaan teknologi. Dengan meningkatnya pengalaman, konsumen memiliki lebih banyak kesempatan untuk memperkuat kebiasaan mereka karena memiliki lebih banyak waktu untuk melakukan perilaku yang terkait untuk selalu memberikan kemudahan nasabah pada penggunaan.

Variabel habit yang dimediasi oleh behavioural intention berpengaruh positif signifikan terhadap adoption dengan nilai T-statistik yang lebih besar dari pada nilai Ttabel, yaitu sebesar 5,397 dan $p$-values $0,000(\leq 0,05)$ sehingga $\mathrm{H} 6$ diterima. Hasil dalam penelitian ini menunjukan bahwa behavioural intention dapat memediasi pengaruh habit terhadap adoption. Sifat mediasi yang diberikan oleh behavioural intention adalah mediasi parsial (part mediation). Artinya, habit dapat memberikan pengaruh terhadap adoption secara langsung walaupun tanpa melalui variabel mediator, namun hanya dapat memediasi secara parsial atau sebagian (part mediation) yang dikarenakan variabel predictor dapat memengaruhi secara langsung terhadap variabel criterion. 
Sejalan dengan beberapa penelitian dari (Venkatesh et al., 2012; Kolodinsky et al., 2004; Eriksson et al, 2008) habit yang berkaitan dengan behavioural intention terhadap adoption yang mana konstruk dari konseptual yang mempunyai hasil dari pengalaman. kebiasaan dalam konteks penggunaa teknologi akan membuat seseorang untuk pengadopsi secara terus-menerus. Namun, saat ini studi mengadopsi proposisi yang menyarankan hubungan yang kuat antara habit dan behavioural intention terhadap adoption yang telah didukung oleh sejumlah penelitian di bidang yang sama bidang yang diminati.

Secara praktis hasil penelitian ini juga memberikan kontribusi penting terutama bagi bank BNI yang mencoba dan menanamkan kepercayaaan pelanggan terhadap mobile banking $\mathrm{BNI}$ ini sehingga menimbulkan kepuasan tersendiri. Pemahaman terhadap perilaku konsumen akan memudahkan penyedia layanan untuk mengembangkan layanan mobile banking secara luas sesuai kebutuhan dan keinginan nasabah. Keinginan berperilaku nasabah seringkali didasarkan pada kemungkinan tindakan yang akan dilakukan sebagai keinginan konsumen untuk berperilaku dalam rangka memiliki menggunakan suatu sistem teknologi mobile banking yang akan membuat nasabah untuk mengadopsi layanan ini. Jadi, nasabah dapat membentuk keinginan untuk mencari informasi, memberitahukan orang lain tentang pengalamamannya dengan suatu layanan dengan cara tertentu. Hal ini menunjukan pentingnya bank BNI untuk memberikan penjelasan secara detail terhadap nasabah yang baru menggunakan mobile banking, sehingga nasabah dapat memahami dan memanfaatkannya untuk kebutuhan untuk transaksi.

Variabel perceived enjoyment yang dimediasi oleh behavioural intention berpengaruh positif signifikan terhadap adoption dengan nilai T-statistik yang lebih besar dari pada nilai T-tabel, yaitu sebesar 3,306 dan p-values 0,001 sehingga H7 diterima. Hasil penelitian ini menunjukan bahwa behavioural intention dapat memediasi pengaruh perceived enjoyment terhadap adoption. Sifat mediasi yang diberikan oleh behavioural intention adalah mediasi parsial (part mediation). Artinya perceived enjoyment dapat memberikan pengaruh langsung terhadap adoption walaupun tanpa melalui variabel mediator. Penelitian ini juga didukung oleh beberapa penelitian yang dikemukakan oleh (Park, 2002; Mardikanto \& Sutarni, 1982; Rogers \& Davis, 2003; Shiau et al., 2014) yang menyatakan kenyamanan yang dirasakan adalah bentuk kesenangan yang dapat mendorong persepsi upaya yang tinggi dan tingkat kecemasan yang lebih rendah sehingga dapat menghasilkan adopsi yang lebih tinggi.

Penggunaan mobile banking dapat menghasilkan kepuasan secara langsung yang dapat mendorong perceived enjoyment pada behavioural intention terhadap adoption nasabah untuk memprediksi perilaku individu. secara praktis hasil penelitian ini juga memberikan kontribusi penting terutama bagi bank BNI yang memberikan kenyamanan yang dirasakan nasabah dalam bentuk kesenangan yang dapat mendorong persepsi upaya yang tinggi dan tingkat kecemasan yang lebih rendah 
sehingga dapat menghasilkan adopsi yang lebih tinggi. Nasabah yang telah memiliki kesetiaan terhadap suatu layanan mobile banking BNI akan memengaruhi sikap nasabah lain untuk melakukan perilaku yang membuat suatu layanan untuk diadopsi, pada mengadopsi suatu layanan yang dipengaruhi oleh hasrat keinginan konsumen untuk mengadopsi suatu layanan untuk melakukannya dengan adanya suatu niat perilaku dalam penggunanya. Hal ini bank BNI perlu menyadari bahwa pelayanan yang ramah dan maksimal akan membuat nasabah merasakan kenyamanan dan kesenangan untuk terus menggunakan mobile banking. Jadi, nasabah dengan mudah bertransaksi kapan saja dan dimana saja tanpa adanya hambatan waktu, nasabah lebih menginginkan hal yang praktis, cepat dan efisiensi karena tujuan dari adanya laynaan digital ini nasabah tidak perlu datang ke bank untuk mengantri karena layanan digital ini yang akan terus berkembang dan memperbaharui setiap fitur yang ada di dalam mobile banking BNI.

\section{KESIMPULAN}

Penelitian ini secara teoritis mengkonfirmasi penelitian sebelumnya, dimana seseorang akan menerima teknologi yang dipengaruhi oleh faktor kebiasaan, perilaku minat, dan persepsi kenyamanan. Secara praktikal, perusahaan perlu beradaptasi dengan kemajuan teknologi. Kualitas layanan mobile banking perlu ditingkatkan agar dapat memenuhi kebutuhan nasabah dalam bertransaksi di perbankan. Pada penelitian selanjutnya disarankan untuk memperluas faktor-faktor pendukung lainnya yang dapat memengaruhi penggunaan mobile banking Bank BNI.

Penelitian tentang habit, perceived enjoyment pada behavioural intention berpengaruh terhadap adoption masih terdapat keterbatasan mengenai ruang lingkup penelitian. Penelitian selanjutnya diharapkan mampu untuk memperluas dan memodifikasi kerangka pemikiran penelitian agar dapat mengukur secara lebih komprehensif atau mengkaji lebih dalam mengenai variabel terkait dalam penelitian ini sehingga menciptakan penelitian yang lebih baik lagi kedepannya.

\section{DAFTAR PUSTAKA}

Ajzen, \& Madden, T. J. (2005). Prediction of goal-directed behavior: Attitudes, intentions, and perceived behavioral control. Journal of experimental social psychology, 22 (5), pp. 453-474.

Alawan A.A., Dwivedi,Y.K., \& Rana.N.P (2017).factors influencing adoption of mobile banking by Jordanian bank customers: ekstending utaut2 with trust. Internasional journal of informational management,pp. 99-100.

Bruner,G..C., \& Kumar A. (2005). Explaining consumer acceptance of hand-held Internet devices, Journal of BusinessResearch 58 (5), pp. 553-558. 
Carpenter D, \& Jane L Reimers (2005). Unethical and Fraudulent Financial Reporting: Applying the Theory of Planned Behavior. Journal of Business Ethics. Vol.60, pp:115-129.

Chen, C. \& Tsai, D. (2007), How destination image and evaluative factors affect behavioural intentions, Tourism Management, Vol. 28 No. 4, pp. 1115-22.

Dai, H. \& Palvi, P.C. (2009), "Mobile commerce adoption in China and the United States: a cross-cultural study", ACM SIGMIS Database, Vol. 40 No. 4, pp. 4361.

Davis F. D. (1989). Perceived Usefulness, Perceived Ease Of Use, and User Acceptance of Information Technology. MIS Quarterly. 13, pp. 983-1003.

Eriksson, K., Kerem, K. \& Nilsson, D. (2008) 'The adoption of commercial innovations in the former Central and Eastern European markets. The case of internet banking in Estonia', International Journal of Bank Marketing, Vol. 26, No. 3, pp.154-169.

Han, H., \& Ryu, K. (2006). Moderating role of personal characteristics in forming restaurant customers' behavioral intentions: An upscale restaurant setting. Journal of Hospitality \& Leisure Marketing, 15(4), 25-54.

Heijen, Venderd (2004). User Acceptance of Hedonic Information Systems. MIS Quarterly, Vol 28 Issue (4). Accessed on March 20th2016. Pp. 695-704.

Hernandez, J.M.C., \& Mazzon, J.A. (2007), Adoption of internet banking: Proposition and implementation of an integrated methodology approach, International Journal of Bank Marketing, Vol. 25, No. 2, hal. 72-88.

Jarvenpaa Sirka L, \& Todd Noam Stracktim (1997). Consumer trust in an store. Information teknology and management.

Jati, Nugroho Jatmiko \& Laksito, Herry (2012). Analisis Faktor-faktor yang Mempengaruhi Minat Pemanfaatan dan Penggunaan Sistem E-Learning. Diponegoro Journal of Accounting, Vol. 1, No. 2.

Jun Wu \& Chai Wan (2003). The Emperical Analysis On The Relationship Between Enterprise Scale And Input Insecity of R\&D. Journal Of Marketing. Pp 11461155

Kim \& Malhotra R.E (2005). Establishment of the vernalization-responsive, winter annual habit in Arabidopsis requires a putative histone methyl transferase. Plant Cell 17: 3301-3310.

Kolodinsky, J.M., Hogarth, J.M. \& Hilgert, M.A. (2004) 'The adoption of electronic banking technologies by US consumers', The International Journal of Bank Marketing, Vol. 22, No. 4, pp.238-259.

Laukanen P., Sinkonen,S., \& Laukanen, T. (2008). Consumer resistence to internet banking: posponers, opponents,and rejectors. Internasional journal of bank marketing 440-445. 
Lu, Y., Zhou, T. \& Wang, B. (2009). “Exploring Chinese users' acceptance of instant messaging using the theory of planned behavior, the technology acceptance model, and the flow theory", Computers in Human Behavior, Vol. 25 No. 1, pp. 29 -39 .

Mardikanto, T. \& Sri Sutarni (1982). Motivasi dan Pengembangan Manajemen. (Kumpulan Buku). Erlanggga, Jakarta.

Neal, D. T., Wood, W., Labrecque, J. S., \& Lally, P. (2012). How do habits guide behavior? Perceived and actual triggers of habits in daily life. Journal of Experimental Social Psychology, 48, 492-498.

Park, S. Y. (2002). An analysis of the technology acceptance model in understanding university students'behavioral intention to use e-learning. Educational Technology \& Society, 12(3), 150-162.

Rogers J \& Davis (2003). The rural non-farm economy, livelihoods and their diversification: issues and options. Chatham UK: Natural Resources Institute.

Rogers, Everett \& Shoemaker Floyd (1971). Communication of Innovations; A CrossCultural Approach. Journal of marketing.

Rogers, Everett \& Shoemaker Floyd (1971). Communication of Innovations; A CrossCultural Approach. Journal of marketing.

Saha GC, \& Theingi H. (2009). Service quality, satisfaction, and Jurnal Manajemen Maranatha behavioral intentions: a study of low-cost airline carriers in Thailand. Manage. Serv.. Qual., 19(3): 350-372.

Scarpi, D. (2010). "Does size matter? An examination of small and large web-based brand communities", Journal of Interactive Marketing, Vol. 24, No. 1, pp. 1421.

Sekaran, U. 2007. Metodologi Penelitian Untuk Bisnis. Edisi Keempat Indeks. Buku 1 dan 2. Jakarta: Salemba Empat.

Shaweeta Pandey \& Deepak Chawla (2018). "Engaging m-commerce adopters in India: Exploring the two ends of the adoption continuum across four m-commerce categories", Journal of Enterprise Information Management. Pp 1741-1751.

Shiau C, Liaw, S. Y., Zhou, W. T., Lau, T., C., \& Chan, S. W. (2014). A interprofessional communication training using simulation to enhance safe care for a deteriorating patient. Nurse Education Today, 34(2), 259 264. doi:10.1016/j.nedt.2013.02.019.

Sigar, Junita Fadhillah (2016). The influence of perceived usefulness, perceived ease of use and perceived enjoyment to intention tu use electronic money in Manado. Jurnal EMBA Vol.4 No.2, Hal. 498-507.

Suryo Notodirjo (2005). "Teknologi Internet Mobile, Seminar Nasional Internet Mobile" - Program Studi Sistem Informasi Fakultas Teknologi Informasi UKSW 
Taylor S \& Todd P.A. (1995). Understanding information technology usage: A test of competing models. Information systems research, Journal of the Association for Information Systems 6(2), 144-176.

Teo, T. S. H. (2001). Demographic and motivation variables associated with Internet usage activities. Internet Research, 11(2), 125-137.

Van Der Heijden, H. (2004). User acceptance of hedonic information systems. MIS Quarterly, 28(4), 695-704.

Van, Marewijk. M (2003). Concepts and Definitions of CSR and Corporate Sustainability: Between Agency and Communion. Journal of business ethics. 44(2)-95-105.

Venkatesh V., Thong J.Y.L \& Xu, X (2012). "Consumer acceptance and use of information technology: extending the unified theory of acceptance and use of technology", MIS Quarterly, Vol. 36 No. 1, pp. 157-178.

Venkatesh, Morris, \& Davis. (2003). User Acceptance of Information Technology: Toward a Unified View. MIS Quarterly, 27(3), 425. doi:10.2307/30036540. 